\title{
Una patología del vínculo amoroso: el maltrato a la mujer
}

RESUMEN: consideramos los malos tratos a la mujer como un emergente de las relaciones' de poder en nuestra sociedad patriarcal, y de la expresión de los roles de género que esta sociedad promueve entre los hombres y las mujeres. Analizamos el vínculo de la pareja en la que se dan los malos tratos como una patología del amor, utilizando los conceptos de "objeto transformacional" de Christopher Bollas y de "reconocimiento" del otro como sujeto de Jessica Benjamin.

PALABRAS CLAVE: Maltrato a la mujer. Violencia. Género. Amor. Psicoanálisis. Subjetividad.
SUMMARY: We consider woman abuse as a result of the power relationships in our patriarchal society, and of the expressions of the gender issues that this society promotes between men and women. We analyze the link of the couple in which ill treatment takes place as a pathology of love, using the concept of "transformational object" by Christopher Bollas and that of "recognition" of the other as subject by Jessica Benjamin.

KEY WORDS: Woman abuse. Violence. Gender. Love. Psychoanalysis. Subjectivity.

\section{Introducción}

Vamos a intentar comprender el fenómeno de la violencia en la pareja, es decir, de los malos tratos a la mujer (porque ésta es la víctima de esa violencia en un $95 \%$ de los casos), dentro de un modelo complejo de explicación de la conducta humana que articula el saber del psicoanálisis, la antropología, la filosofía, la sociología y la psicología con los modernos estudios de género.

La violencia familiar es un emergente de las relaciones de poder dentro de la familia. Como uso abusivo del poder, la violencia masculina está atravesada por legitimaciones culturales que proceden de los diferentes modelos de socialización para hombres y mujeres, esto es, de la adquisición en nuestra cultura patriarcal de la denominada identidad de género. La violencia surge como respuesta a las diferencias entre las expectativas no satisfechas que un género ha depositado en el otro, de ahí que se le denomine también violencia de género.

Sin embargo, para comprender la especificidad del vínculo que se establece en la pareja donde se producen los malos tratos no nos basta con apelar a los efectos de la socialización, sino a cómo éstos se inscriben en un psiquismo determinado. Es por ello que intentaremos exponer desde el psicoanálisis, el origen de la subjetividad humana, 
origen ligado a la agresividad, así como el fenómeno del amor y el vínculo de pareja, e intentaremos desentrañar los nudos de una relación que incluye la violencia como un componente esencial de la misma, articulando dos conceptos de diferente procedencia: el concepto de "objeto transformacional" de Christopher Bollas, y la teoría sobre el reconocimiento del otro como sujeto, y la dominación como fracaso de este mismo reconocimiento, que debemos a Jessica Benjamin.

Resulta obvio recordar que sin amor no hay malos tratos, por lo que concebimos los malos tratos en la pareja como una patología del vínculo amoroso, un fracaso de la comunicación.

\section{La subjetividad humana}

La construcción de la subjetividad en el ser humano es un proceso complejo que requiere determinadas condiciones para que se lleve a efecto, la más importante de ellas es que la crianza sea realizada por humanos. La experiencia de los niños salvajes en la Francia del siglo XIX (1) nos ratifica que el ser humano requiere de la presencia y el cuidado de otros semejantes para adquirir el lenguaje y el pensamiento, condiciones que dan cuenta de su humanidad (2). En todas las sociedades humanas esta crianza humanizadora se lleva a cabo en la familia, cualquiera que sea quien se considere miembros de ésta (3).

La presencia de otros, de semejantes, facilita entonces la adquisición de la subjetividad mediante un mecanismo que Freud (4) llamó identificación, y que definió como el primer lazo afectivo con el otro.

Es decir, el bebé aprenderá de los que le rodean, fundamentalmente de su padre y de su madre, a través e interacciones repetidas, todo un repertorio de conductas, el lenguaje para nombrarse a sí mismo y nombrar sus sentimientos, y las formas como se defienden sus mayores de la angustia o de la frustración. Este aprendizaje no se realiza de una manera lineal, como cabría pensarse, sino a través de la identificación, de un lazo afectivo con el objeto de cuidados que contiene elementos de satisfacción y de frustración, sentimientos de amor y de odio, elementos conscientes y otros inconscientes.

Los más recientes estudios sobre desarrollo infantil hacen hincapié en la importancia de las conductas de apego entre el bebé y su cuidadores, para establecer un pronóstico sobre su comportamiento futuro, y su capacidad de reflexionar en sí mismo y en el otro (5) así como del mundo de las representaciones de los padres como fuentes de transmisión de sentimientos, y de la identidad sexual (6).

Desarrollaremos brevemente las teorías psicoanalíticas sobre el desarrollo infantil incidiendo en aquellos aspectos que más nos interesan en el tema que nos ocupa. 
En un primer momento, el bebé y el objeto que lo cuida forman una unidad indiferenciada, el niño/a no tiene noción de los límites de su cuerpo, cuando tiene necesidades aparece otro que las cubre, de forma más o menos acertada. Este primer momento de simbiosis, será el núcleo del narcisismo. Stern demuestra cómo esta "interrelación afectiva" entre la madre, especialmente predispuesta al activarse en ella la identificación con su propia madre, y el bebé, determinará el desarrollo temprano del sí mismo. A los ocho o nueve meses el bebé descubrirá que fuera de él existen otras mentes, y que esas mentes separadas, pueden compartir un estado similar, iniciará el reconocimiento del yo y del otro, otro considerado no como objeto de sus necesidades, sino como sujeto con necesidades propias.

Este proceso de individuación- separación, en el que se han centrado casi todos los autores que tratan del desarrollo infantil (Winnicott, Mahler, Tustin, Bowlby, Stern, Fonagy, Steele, Lebovici), es paralelo a la adquisición de la identidad de género y el desarrollo de una moral autónoma.

El niño deambulador tiene ya adquirida su identidad de género. Hasta el segundo año de vida se sigue experimentando una tensión entre la afirmación del sí mismo y el reconocimiento del otro: al tratar de establecerse como una entidad independiente el sí- mismo debe sin embargo reconocer al otro como un sujeto igual a él, para ser reconocido por ese otro. Esta tensión constante entre reconocer al otro y afirmar el sí mismo se establece si existe "constancia del objeto", término que acunó Mahler para expresar la experiencia de que la agresividad hacia el objeto no destruye al objeto real. Como señala Jessica Benjamin (7), psicoanalista, profesora de la Universidad de Nueva York, "Cuando la destructividad no daña a la madre ni al sí mismo, la realidad externa entra en el campo visual con un contraste claro y tajante con el mundo de la fantasía".

El objeto pasa a ser considerado como sujeto, aunque la tensión permanecerá siempre entre el reconocimiento de sí y del otro como sujeto, porque la agresividad está en el origen de la subjetividad humana, "desde un punto de vista intersubjetivo, el choque de dos voluntades es inherente a toda relación entre sujetos, un momento ineluctable que todo sí- mismo tiene que enfrentar", continúa Benjamin más adelante.

Ahora bien, no siempre es posible el establecimiento de esta diferencia fundamental, para nosotros, en el hombre maltratador en la tensión entre el reconocimiento del objeto como sujeto triunfa la consideración del otro como objeto, debido, entre otras determinaciones, a la incorporación de los valores de género masculinos (hipermasculinidad de los maltratadores), y a la dificultad de establecer el proceso de individuación, conservando la simbiosis con el objeto como parte inseparable de su identidad, y su pérdida como una devaluación narcisista insoportable. 
Analicemos con más detalle este proceso. Como vimos, la primera relación del bebé con el objeto que le provee de cuidados (en nuestra cultura sigue siendo fundamentalmente la madre), es una relación de dependencia extrema, el niño establecerá un vínculo con la persona que lo cuida, que será el núcleo de su identidad futura.

A este objeto Christopher Bollas (8), psicoanalista discípulo de Winnicott y miembro del Grupo Independiente de la Sociedad Psicoanalítica Británica, le llama "objeto transformacional", y tiene que ver con la experiencia temprana de un objeto primero que transforma el mundo interior y exterior del sujeto, una etapa simbiótica donde el yo y el otro no están diferenciados. "Esta experiencia del yo que consiste en ser transformado por el otro permanece como una memoria que puede ser reescenificada en experiencias estéticas o en objetos que prometen un cambio...".

"Aún no individualizada plenamente como otra, la madre es experimentada como un proceso de transformación, y este aspecto de la existencia temprana pervive en ciertas formas de búsqueda de objeto en la vida adulta, en que éste es requerido por su función de significante de transformación". El espacio transicional de Winnicott sería la continuación natural, como señala Sanfeliu (9), del periodo transformacional.

Cuando la madre ha fracasado en esta función de transformar el ambiente del bebé, "en la vida adulta, lo que se ansía no es poseer el objeto: más bien se lo busca para entregarse a él como un elemento que altere el self... el objeto como transformador ambientosomático del sujeto. La memoria de esta temprana relación de objeto se manifiesta en la búsqueda, por parte de la persona, de un objeto (persona, lugar, suceso, ideología) que "traiga la promesa de transformar el self", según nos dice Bollas en la obra ya citada. Se trata de una experiencia afectiva intensa que equivale a un reconocimiento interior de la necesidad de reparación del yo; como tal es una búsqueda de salud, un poco maníaca.

Y continua el autor: "No debe sorprender que diversas psicopatologías emerjan del fracaso (según expresión de Winnicott) en ser desilusionado de este vínculo" (el subrayado es nuestro). Es decir, nos encontraríamos con que, de no producirse el adecuado pasaje hacia del objeto transformacional hacia el objeto transicional, debido a fallas en la interacción con la madre, entonces, en la vida adulta, "ciertas formas de erotomonía quizá sean ensayos de establecer el otro como el objeto transformacional".

Julia Kristeva (10) sostiene que «la dependencia del hombre respecto de la mujer es fundamental, ella es un objeto erótico que incluso puede ser dominado y despreciado, pero del cual no puede prescindir. Esta es una adicción del erotismo masculino, -considera Kristeva-, que está dominado por las vicisitudes del objeto materno, vivido como todopoderoso" (subrayado nuestro). Compartimos esta apreciación de Kristeva; esta dificultad de prescindir de una expectativa hacia un objeto materno todopoderoso es la que encontramos, de forma extrema y unida a otros rasgos psicopatológicos, en los hombres maltratadores que no pudieron reducir el 
poder de la madre ni reconocerla como sujeto de necesidades y deseos propios. No hay un aprendizaje, ni una representación de la madre como sujeto, y la mujer que viene a ocupar ese mismo lugar de objeto que calma, que responde literalmente a las expectativas de omnipotencia del varón angustiado, constituye lo que Bollas llama "objeto trasformacional".

En la situación de pareja se repite la imposibilidad del reconocimiento; la dificultad de estos hombres de reconocer su íntima dependencia de su compañera se explica porque esta dependencia amenaza su propia representación de la virilidad, y su identidad masculina. Esta negación acentúa la externalización de la culpa que sigue a la violencia. El maltratador parece justificar: "No soy yo, sino ella" quien fracasa en el apaciguamiento.

En circunstancias normales, como dijimos, la etapa de dependencia extrema con el otro dura poco; la demora en la respuesta de la madre, la ausencia de ella y su posterior regreso, traerán consigo la experiencia de frustración, junto con la agresividad y la progresiva separación del niño de este objeto privilegiado hasta concebirlo como una entidad por derecho propio, como decía Winnicott, y no sometido a nuestro control mental. Este es un proceso no exento de angustia pero que desembocará, en permanente tensión, en el reconocimiento del otro como sujeto de deseos y de necesidades, otro que está ahí afuera, en el mundo, a través del cual se realiza también la distinción entre realidad interna y externa.

Cuando el niño reconoce que el objeto es independiente de él, cuando tiene experiencia de su pérdida, entonces lo nombra. Para que haya lenguaje ha de haber separación del niño y de la figura de cuidados con la que se haya vinculado, se nombra aquello que se pierde. Con la separación de la madre el niño dirá mamá, papá.

Es decir, el lenguaje viene allí donde aparece la angustia de separación, esto es importante retenerlo para explicar la violencia familiar. En la pareja donde se producen los malos tratos no hay lenguaje que hable de la angustia y aparece la violencia como intento de "pegarse" al objeto, o de despegarse de él

La dificultad de reconocer a la mujer como un sujeto autónomo, inhibe el lenguaje, que aparece como innecesario: si el objeto está dentro no hace falta articular palabra para que atienda. Pero el objeto está afuera, y la frustración consecuente con este hecho, la imposibilidad de "dominarlo" por entero, produce el paso a la actuación: la violencia. Tal y como señala Benjamin (11), "si fracasa el reconocimiento hay dominación".

Hemos visto que a partir del primer año de vida el niño y la niña toman conciencia tanto de su sexo anatómico como de otras partes de su cuerpo y de las diferencias entre los sexos (12). Además, poco a poco irán incorporando por socialización e identificación los valores asignados a uno y otro género, que en nuestra cultura patriarcal son complementarios entre sí (binomios como: dominación-sumisión; independencia-dependencia; agresi- 
vidad- dulzura...van ligados a los estereotipos del género masculino y femenino, respectivamene). Esta identidad de género es inseparable de la adquisición de la conciencia moral y de las costumbres (13).

Durante el segundo año de vida, niño y niña habrán adquirido el la identidad de género. Con más o menos vicisitudes tendrán conciencia de que pertenecen al género masculino o al femenino y de las conductas y aptitudes que se espera de ellos en relación con este hecho.

\section{Estudios de género y violencia familiar}

Nuestra sociedad occidental es androcentrista y patriarcal. Esto quiere decir que lejos de interpretar las diferencias entre los sexos como meras diferencias, ha distribuido entre ellas un valor en positivo para lo masculino, y en negativo para la feminidad, haciendo de lo masculino el valor universal. Como dice François Héritier: "las categorías de género, las representaciones de la persona sexuada, el reparto de las tareas tal como las conocemos en las sociedades occidentales, no son fenómenos de valor universal generados por una naturaleza biológica común, sino construcciones culturales" (14).

A partir de las diferencias biológicas, es decir, de la maternidad y la diferente posición en la crianza de los niños, el hombre, en todas las culturas, ha inventado a la mujer, la ha hecho depositaria de una serie de representaciones que la destinan a configurarla de un modo determinado y no de otro. Se trata de lo que Bordieu llama "violencia simbólica", "violencia amortiguada, insensible, e invisible para sus propias víctimas, que se ejerce esencialmente a través de los caminos puramente simbólicos de la comunicación y del conocimiento $\mathrm{o}$, más exactamente, del desconocimiento, del reconocimiento, $\mathrm{o}$, en último término, del sentimiento" (15).

Podemos decir con Lorite Mena (16) que la mujer es una invención de los hombres; una invención, una representación simbólica que tiene como función garantizarles el poder en la sociedad asegurándose un sostén afectivo sexual determinado. Para ello en el proceso de socialización y adquisición de los roles de género las niñas fueron adquiriendo una serie de características que las dotan para dar a los hombres aquello que ellos perciben como formando parte de sus más íntimas necesidades: amor eterno (madre) y satisfacción sexual (puta en su versión más prosaica).

También el hombre ha inventado una masculinidad determinada, que se diferencia radicalmente de la feminidad. "Partimos de una "androginia inicial" dirá Corsi (17), la disponibilidad en cada ser humano de adquirir los rasgos atribuidos culturalmente a uno u otro género. Los estudios antropológicos no hacen sino confirmar esta disponibilidad y plasticidad identificatoria (18). Stoller defiende una fuerte identificación con la madre del 
varón, que explica muy bien la reacción contra la feminidad de los hombres adultos, que han de identificarse como no-mujeres. Dato éste que la antropología nos ha enseñado a valorar en su extensión. Los ritos de paso para los hombres son verdaderos adiestramientos en el modo de abandonar el mundo femenino de la infancia, y adentrarse en los valores con que cada cultura ha ido elaborando su representación de lo masculino (19).

Las diferencias de género se muestran en todos los factores de la vida. Sabemos, por la psicología diferencial, que desde la más temprana infancia los adultos diferencian a niños y niñas y nombran sus sentimientos de diferente modo. El llanto de un bebé, cuando no existen signos externos que nos permitan afirmar que pertenece a un sexo u otro, será interpretado por los adultos desde sus propias expectativas de género según se les diga que es una niña, -"llora porque está triste", concluirán -, o un niño, - "llora porque está enfadado"-, como nos describe Braconnier (20) haciéndose eco de un famoso experimento. Así las emociones tendrán género, serán nombradas de diferente modo para unos y otros, al igual que las respuestas que dan los adultos que nos educan en unas y otras emociones. De este modo, en los niños se fomentará la agresividad, la actividad, la transgresión y la fuerza; en las niñas la obediencia, la pasividad, la ternura, y el acatamiento de la ley. Este proceso de socialización se hace con relativo éxito en nuestras sociedades. La diferencia entre los géneros comporta distintos modos de expresión del malestar, que vuelven a reproducir las formas de apropiación de la identidad de género (21).

Sin embargo, esta agresividad, más reprimida en las niñas que en los niños, es un componente fundamental de la subjetividad humana; está presente en todas las especies animales y en el ser humano, y forma parte de su repertorio de conductas. Para Freud y el psicoanálisis, la agresividad es parte fundamental del origen de la subjetividad: para separarse del objeto, como dijimos, el niño deberá oponerse a él, diciendo NO. En el infante, el No se aprende antes que el sí, en su evolución es importante esa etapa de oposicionismo que para Piaget será el germen de una subjetividad independiente y de una moral autónoma.Además la agresividad está ligada a los sentimientos, a la afectividad y a la sexualidad; el niño y la niña sentirán agresividad contra el rival que pretende que pierda parte del amor de su objeto de adoración, durante el desarrollo del Complejo de Edipo. Es una experiencia constatada la rivalidad fraternal, el deseo del niño (a veces actuado de diferentes modos) de matar al hermanito que lo desposee del amor, antes exclusivo de los padres.

La agresividad tiene pues un carácter necesario y adaptativo. Como señala Echeburúa (22) desde el modelo cognitivo conductual: "La ira tiene un efecto energizante que facilita la adopción de las conductas adecuadas para hacer frente a la frustración". Será la cultura, el aprendizaje social, la adquisición de la identidad de género, la que moldeará la agresividad humana de distintos modos según las culturas y las sociedades (23). En la nuestrà, que es la que nos ocupa, a los hombres se les reforzará el rol de agresores y a las mujeres el de víctimas. 
A través del cine, medios, lenguaje, la mujer aprende a controlar la agresividad de modo tan radical que hasta la propia agresividad adaptativa, aquella que le permitiría defenderse de la agresión o afirmarse en un simple No, se vuelve contra ella misma, y no hacia el exterior. De este modo, en los hombres predominan las conductas agresivas mientras la mujer vierte la agresión hacia adentro. En consecuencia, y a la espera de que se produzca la deconstrucción de la psicopatología a la luz de los estudios de género, podemos convenir que los hombres acusan patologías de la acción (alcoholismo, drogodependencias, maltratos, conductas de riesgo...) y las mujeres depresiones, somatizaciones y trastornos alimenticios, como expresión de su diferente educación sentimental, ligada a las expectativas sociales sobre uno y otro género.

En el momento actual, aunque existen cambios en las relaciones entre los sexos, los roles tradicionales permanecen en el imaginario cultural y en la identificación de género de los hombres y de las mujeres. Es más, la identificación con esos roles de género y la lucha por desidentificarse de ellos son un elemento más de confrontación y de angustia en la dinámica de los actuales vínculos de pareja.

\section{Parejas}

Aquellos niños y niñas que dejamos en los tres o cuatro años, identificados a lo que para nuestra sociedad es ser un hombre y una mujer (los valores de género), se hacen adolescentes, las hormonas acuden en tropel a dotarlos de los caracteres sexuales secundarios, y se enamoran actualizando una reedición de las primitivas elecciones de objeto y de los posteriores vínculos afectivos triangulares que acontecen en las vicisitudes del complejo de Edipo.

El amor es el vínculo que une a las parejas, incluidas aquellas en las que se producen los malos tratos, es decir, la violencia familiar se produce sobre el fondo de unas relaciones afectivas. Es más, el perfil del hombre maltratador es aquel que no usa la violencia fuera de la pareja, excepto si se trata de psicópatas, alcohólicos y otros toxicodependientes, sus vecinos dirán de él que es un buen hombre (24). Esto podría llevarnos a pensar que los malos tratos, tanto en el hombre maltratador, como en la mujer maltratada que persiste en no abandonar a su pareja, porque la ama, son una patología del vínculo amoroso.

Cuando nos enamoramos dotamos al otro, mediante mecanismos de proyección, de las virtudes y de los valores más excelsos. É es todo para nosotros, el otro viene a ocupar el lugar idealizado que ocuparon los padres infantiles. De ahi que muchas veces nos parezca que lo conocemos de toda la vida, de ahí que se diga que encontramos la media naranja: partidos en dos, recuperamos con el amor la otra mitad. Así, en el enamoramiento, el otro ocupa el lugar del Ideal del Yo (25), se produce un aumento del narcisis- 
mo, puesto que, si el amor es correspondido, poseemos aquello que más valioso nos parece, aquello que nos completa, que nos hace mejores. Es la euforia del enamoramiento, la omnipotencia de los enamorados.

Pero, al mismo tiempo, la necesidad del otro genera una conciencia mayor de vulnerabilidad, de incompletud, que va a producir agresividad, a causa de la herida narcisista que esta conciencia de que dependemos del otro nos genera, como ya en 1.921 nos enseñaba con su habitual agudeza Freud. (26).

Situamos pues el conflicto entre el amor y el odio como estructural en la pareja, y la agresividad que llega al acto un polo o extremo de ese continuo que tiene por polo opuesto la agresividad atribuible a la que la presencia del otro nos genera. Este lazo ambivalente, compuesto de amor y de odio, forma parte de cualquier enamoramiento, todos sentimos ambos sentimientos, en mayor o menor grado, de ahí los dichos populares que nos advierten sobre la cercanía entre ellos. Son aquellos a quienes más queremos, nuestros otros significativos, sobre quienes actúa con más virulencia nuestra irracionalidad, y la familia, con su exposición continua a ser el objeto de nuestras expectativas más narcisistas y al fracaso inevitable de éstas, el lugar donde los determinismos inconscientes tienen una actuacion privilegiada.

Sin embargo, como expuse en otro lugar (27), el enamoramiento no puede durar toda la vida porque el otro defrauda siempre (desidealización). De ahí que, poco a poco, ese enamorado pueda darse cuenta de que su amada/o no es tal y como él imaginaba, sino que es otro distinto. El descubrimiento puede arrastrar tras de sí al amor (desenamoramiento), o conservar la posibilidad de seguir amando de forma más ambivalente, más realista, a la persona de carne y hueso que tenemos al lado. La realidad del otro nos hará unir las virtudes con los defectos, el amor con el malestar que nos genera que no responda a nuestras expectativas, porque eso comporta que nos alejamos de nuestro ideal narcisista, lo que nos hace sufrir, disminuyendo nuestro valor. Se trata de pasar de la pareja como UNO, mitificación del amor romántico, a la pareja como dos sujetos con sus diferentes ideales, que habrán de quedar en parte insatisfechos.

Esta mezcla de sentimientos ambivalentes no se da igual en las parejas cuyo vínculo amoroso tiene una serie de características que vamos a ver aquí, es decir, en la pareja formada entre el maltratador y su víctima. Entre ambos se ha establecido un vínculo apasionado, de amor-pasión, en el que cada cual ocupará para el otro el lugar de satisfacción de una necesidad determinada de fusión, de confusión con el otro, diferente para el hombre y para la mujer maltratada. Unas necesidades que están prescritas por las expectativas de género, de lo que ha de ser un hombre y éste debe esperar de una mujer, y de lo que una mujer es y debe esperar de un hombre.

El hombre maltratador es un hombre identificado con los valores machistas de la masculinidad, es decir, vive como egosintónica su parte violenta, dura, agresiva, fuerte, 
pues no ha desarrollado la capacidad de empatía, de identificación con el otro para lograr comprenderlo, y vive como un empuje a la feminización, temida, la sensibilidad, el diálogo, los cuidados a su compañera (28). La renuncia de este hombre a la violencia le hace caer en una temida feminización al aceptar valores tradicionalmente asignados a las mujeres: comunicación, diálogo, cuidados... lo cual dificultará enormemente su tratamiento. Según se cita en "La violencia familiar. Actitudes y representaciones sociales", de la Asociación Pro derechos Humanos, menos de un $1 \%$ de estos hombres acuden a tratamiento, y la mitad de ese $1 \%$ lo abandona porque han conseguido manipular a la mujer y volver.

Este hombre es un sujeto que ha desarrollado determinados aspectos de su identidad adaptándose a las normas sociales (recordemos aquí el concepto de falso self de Winnicott), un desarrollo que puede verse en sus logros profesionales o en sus relaciones con otros hombres, pero que permanece ligado a un objeto (que viene a estar representado por la mujer elegida) con características de dependencia simbiótica que no puede reconocer. Para sostener esta situación ha debido escindir dos partes de sí mismo que son irreconciliables. "La escisión indica una polarización en la cual los opuestos (en especial lo bueno y lo malo), ya no pueden integrarse", dirá Benjamin, " en la escisión, los dos lados aparecen representados como tendencias opuestas y distintas, de modo que el sujeto sólo tiene acceso a ellas como alternativas". Estamos hablando de una escisión en el yo del maltratador que se corresponderá con una escisión del objeto, es decir, de la mujer. Ninguna de estas dos partes quiere saber de la otra, de la que está separada, porque es contradictoria con ella. La dependencia del hombre maltratador de la mujer objeto de su amor no puede ser reconocida por él, por la amenaza que la dependencia implica para su masculinidad, pero sí actuada en el circuito de la violencia. Esta dependencia reprimida y luego separada, ha dejado su huella en una inseguridad que forma parte del carácter de estos hombres, de la que se defienden adoptando formas autoritarias y machistas.

El reconocimiento de esa parte maldita, dependiente del objeto, pues recupera con él parte de su narcisismo, amenaza una virilidad basada en la adopción de conductas de "hombre".

Veamos qué parte es ésta. A nuestro entender, el maltratador ha depositado en la mujer las características de un objeto primigenio, el objeto de simbiosis que no vivió con su madre, de quien no pudo separarse porque no fue efectivamente constituida como sujeto de amor. Este hombre, como vimos, espera inconscientemente que una mujer, consecuentemente con la distribución de las expectativas de género, calme su angustia y su dolor, y sostenga la parte más dependiente y simbiótica de él. Esta mujer no constituye para el hombre el ideal del yo, como en otros tipos de amor, sino algo más primitivo, menos evolucionado, un objeto indiferenciado al que tiene que tender, una prótesis que le salva de su precaria subjetivación. Dice Christopher Bollas: "Si bien no hay disponible ningún recuerdo de la experiencia del infante con su madre, la búsqueda del objeto transformacional, y la designación del que ha de rescatar una transformación ambiental, es una memoria del yo... de una singular manera éste es el objeto del yo con exclusividad, 
y puede incluso repugnar, o ser indiferente a la experiencia subjetiva que la persona tiene de su propio deseo. Un jugador vicioso es compelido a apostar en contra de su voluntad...". Destacamos con el subrayado esta alusión específica al carácter compulsivo de la búsqueda del objeto que señala Bollas. "Tan pronto como las tempranas memorias del yo son identificadas con un objeto que es contemporáneo, la relación del sujeto con el objeto se puede volver fanática, pues está acompañada de que el objeto producirá un cambio"(29).

Pero para reducir a la mujer que ha elegido a un objeto transformacional, el maltratador deberá ir convirtiéndola previamente en objeto, es decir, privándola de su subjetividad. Lo que, por otra parte, coincide con el proceso que viene haciendo el patriarcado desde hace siglos: convertir a la mujer en un objeto de deseo del hombre. El hombre así caracterizado, cuando posee a esa mujer-objeto que busca, para recuperar una ilusión narcisista de sí, se dedicará a aislarla de los otros (las mujeres se quejan de que el marido les prohibe salir, que sus únicas relaciones han quedado reducidas a los hijos y a su marido, que éste odia a la familia de la esposa y ha conseguido que mantenga pocas relaciones con ella), a dessubjetivarla, a moldearla de acuerdo a los rasgos que desea para su objeto, siguiendo un proceso largo y doloroso para ella. La des-subjetivación de la víctima es común en todos los casos de violencia, sea ésta familiar o social. Entre los nazis, a los judíos se les uniformaba y dejaba sin pertenencias para privarlos de identidad, de pasado y de futuro, objetivándolos para facilitar así el ejercicio de la violencia sobre ellos $(30,31,32)$. Como señala Lorente Acosta (33), el hombre procura entonces un proceso de "aislamiento social de la esposa", un "ataque contra las conexiones de identidad del pasado", y un "ataque contra la identidad actual, criticando y recriminando" a su mujer que no cumple con sus expectativas sobre el papel y el comportamiento que espera de ella dentro de la pareja.

Este proceso de convertir a la mujer en objeto, lo realiza el varón a la espera de que cuando tenga necesidad de ella ésta le responderá tal y como debe hacerlo: como un eco, transformando su medio como él desea y apaciguando su angustia. Cualquier acontecimiento exterior puede provocar en el hombre una regresión hacia ese aspecto escindido de su self e iniciar la búsqueda del objeto apaciguador que representa para él su esposa: una discusión en el trabajo, en el bar, el fútbol...

Como vemos, para la mujer, satisfacer estas expectativas es imposible. La mujer, por más que el circuito de la violencia la haya desposeído de subjetividad, por más que aumente su indefensión (según el modelo de Selligman), seguirá siempre, bien a su pesar en algunos casos, respondiendo de modo distinto al esperado.

Es ahí cuando aparece la violencia. El objeto no transforma, no responde, y el narcisismo se ve amenazado, la ira aparece como forma energizante de recuperar el narcisismo devaluado por la pérdida de ese objeto deseado, y como respuesta a la frustración que se produce. La no presencia del objeto transformacional comporta sentimientos de abandono y de pérdida, como lo era la separación de la madre. 
"La hostilidad deriva de actitudes y sentimientos (de maldad, venganza, cinismo...) desarrollados por una evaluación negativa generalizada de la conducta de la pareja, que generan un impulso a hacer daño", dirá Echeburúa. El diálogo, "que parece en sí mismo constituir una renuncia a la agresividad" (34) está ausente, al no haber reconocimiento del otro como interlocutor. Pero tras la descarga de la violencia, y el temor a perder al objeto, lo que aparecerá en escena será la parte más adaptada de la personalidad masculina, aquella siempre separada de la anterior, y el hombre prometerá a la mujer no "caer" en esas conductas, le dirá que la ama, que la necesita, que está loco por ella, que todo eso es amor.

La mujer, tras la crisis de malos tratos, amenaza con el abandono; Sin embargo, el hombre ha recuperado su hombría con la violencia, y está calmo. Hemos de señalar que observamos conductas de descarga semejantes en pacientes borderline que se auto-reparan narcisísticamente mediante conductas de acción como sexualidad compulsiva, abuso de alcohol y cocaína buscando efectos euforizantes y desinhibición verbal y conductual (sexual o agresiva).

En la relación amorosa entre un maltratador y su víctima existe una dificultad poderosa de unir la visión idealizada del otro con el otro de la realidad, no produciéndose, en cierto sentido, la desidealización.

La parte disociada del hombre esperará siempre su objeto simbiótico apaciguador, y la experiencia de la realidad de que éste no existe no se convertirá en un aprendizaje, puesto que está escindida de esa necesidad y se inscribe en otro lugar. El objeto bueno y el malo están separados, sin que se produzca una integración que permita la ambivalencia, la desidealización, la culpa y la depresión.

Ese modo de satisfacer sus necesidades narcisistas toma la forma de una repetición, de un destino, una inclinación que pese a que nos lleva a la desgracia no puede evitarse. "No puedo evitarlo", es más fuerte que yo..." serán frases frecuentes. Se trata de una neurosis de destino: como la gente que repite una vez y otra sus malos encuentros. El camino de ese goce está horadado en el cuerpo con un surco indeleble que atrae a la circulación de las pulsiones por él hacia una descarga inmediata y violenta.

De este modo se reproducirá el circuito de la violencia, que fenomenológicamente han descrito la mayoría de los autores que se ocupan del tema.

Las fases del maltrato que se identifican son:

a) Tensión creciente: agresión verbal leve. Aislada, la mujer procurará mecanismos de protección para evitar la crisis.

b) Agresión aguda: descarga incontrolada de tensiones. Episodio de malos tratos. La mujer no buscará ayuda hasta pasadas al menos veinticuatro horas de la agresión, lo que se llama "el síndrome del paso a la acción retardada", por vergüenza, temor...

c) Fase de amabilidad y afecto: se caracteriza por una situación de extrema amabili- 
dad, "amor" y conductas cariñosas por parte del agresor: "luna de miel". Es una fase bien recibida por ambas partes, durante ella se produce el proceso de victimización completa de la mujer. Esta fase actúa como refuerzo positivo para el mantenimiento de la relación. El agresor muestra su arrepentimiento y realiza promesas de no llevar a cabo algo similar. Piensa, en efecto, que será capaz de controlarse y que la mujer nunca volverá a comportarse de manera que sea necesario agredirle de nuevo. Actúa aquí la separación de la otra parte simbiótica, y no existe, para ninguno de los dos participantes, posibilidad de unir la secuencia completa, modificando la relación.

Esto es así porque en este tipo de vínculo se pone en juego, al igual que en todo síntoma, algún tipo de satisfacción, una satisfacción posible, que hace difícil disolverlo. Como en el sado- masoquismo donde, para Stoller, "la perversión, como la perla que rodea el grano de arena, se desarrolla mediante el placer sensual, a partir del dominio de lo que en otras circunstancias sería una angustia intolerable"(35); lo intolerable para el hombre maltratador es la renuncia al encuentro con su objeto trasformacional, es decir, la constatación de que nunca, ni antes ni ahora, hubo ni habrá los cuidados que él anhela. Para ambos el ciclo descrito constituye una adicción, un círculo repetitivo, como para el toxicómano el abuso de la sustancia que no puede abandonar.

No podemos extendernos en el estudio de las familias donde se producen los malos tratos, en el aspecto transgeneracional, en la transmisión de determinados roles de género, en la compulsión a la repetición de las mujeres maltratadas en el hogar que buscan y eligen como pareja hombres golpeadores. Estela V. Weldon (36) y Louise Kaplan (37) hacen una aproximación a algunos aspectos del tema, acercándonos a un concepto de perversión femenina donde el maltrato de la madre a los hijos, a su propio cuerpo (mediante daño, mutilaciones, prostitución, o cirugía estética compulsiva), pone de relieve que la perversión femenina tiene rasgos diferenciales respecto a la masculina, al estar enraizada en una devaluación íntima del género transmitida desde las abuelas a las madres. En la mujer maltratada podemos encontrar rasgos de esta perversión, pero dejo para otro momento este polémico aspecto del tema.

Queremos añadir que para estos hombres, de acuerdo a los estereotipos de género adquiridos, los hijos forman parte de la mujer, no siendo reconocidos como sujetos iguales, de ahí que puedan acabar con sus vidas en respuesta o venganza ante la separación y/ o rechazo de la madre.

\section{¿Qué sucede en la mujer?}

Lo que sigue a continuación se refiere a las mujeres que soportan los malos tratos sin romper el vínculo, o que, a pesar de intentar romperlo, permanecen en él ante el temor a hacerlo realmente, en lo que sin duda es el prototipo de un vínculo adictivo (38). Sin 
embargo, a veces, en la elección de la pareja hay errores, ofallidos, y el hombre encuentra una mujer que no responde a la victimización como él espera, rompiendo la relación apenas se dan los primeros episodios de violencia.

Según distintos estudios sociológicos existe un 30\% de mujeres maltratadas y el $50 \%$ de ellas, es decir, la mitad, sigue viviendo con su pareja. En España se producen en el año 2.000 un $22,7 \%$ más de delitos contra las mujeres que hace 10 años. Esto si hablamos sólo de denuncias formales, aunque sólo entre el $5 \%$ y el $10 \%$ de los maltratos llegan a denunciarse alguna vez, quizás porque las mujeres saben que el $82 \%$ de los maltratadores denunciados queda sin condena (datos publicados en el diario El País el 26 de febrero de 2.000). Además, sabemos que pasan hasta 10 años de media antes de que se denuncien los malos tratos y que, después de una denuncia que funciona a veces como amenaza, y que contiene la expectativa implícita de que actúe con un efecto disuasorio, las mujeres siguen conviviendo durante largo tiempo con el marido en espera de un cambio. Ambos esperan un cambio. Un cambio de difícil construcción, pues en lo que se hayan inmersos es en una repetición sin fin, en un tiempo inmovilizado.

En estas mujeres hay una especie de vacío interior, una precariedad de contenidos psíquicos que responde a una historia donde su "experiencia subjetiva" ha sido sistemáticamente negada para adaptarse a las demandas de otro (madre/padre, posteriormente el marido), como viene preestablecido en las expectativas de género asumidas. Este vacío le resulta más intolerable que la dependencia de un hombre cuyo maltrato, también debido a su propia historia familiar previa, ella interpreta como un acto de amor y de dependencia. La mujer percibe la debilidad del otro y se coloca frente a él como una prótesis, un sostén, un refugio, y en ese acto satisface los íntimos anhelos de su feminidad.

En esto consiste, en parte, el enigma de la permanencia de la mujer víctima de los malos tratos con su marido maltratador. Algunos han hablado del llamado masoquismo femenino, pero no voy a entrar aquí, ahora, en esa polémica. De lo que se trata es de que el sufrimiento actual es más tolerable que el sufrimiento fantaseado de la separación, con la consiguiente experiencia de su vacío (apenas adivinado éste, en el tratamiento aparecerá la temida pregunta "¿quién soy yo?”, "yo no soy nadie”), y de su dependencia. El drama externo sustituye y hace soportable el interior. En esa otra escena podemos apreciar el latrocinio del self, en palabras de Bollas, que se ha efectuado sistemáticamente sobre ella, de manera que su subjetividad se ha visto dañada al negársele la experiencia propia, las palabras para nombrar sus sentimientos. Estos quedarán sin identificar muchas veces, afectos sin representación que se expresan en forma de angustia, una angustia que se aminora al proponerse como objeto de otro y responder así a las expectativas de género que suplen con una identificación imaginaria su subjetividad.

A pesar del dolor actual, la mujer maltratada permanece ligada al maltratador porque el reconocimiento de la realidad total del hombre y la separación conllevaría para la mujer la 
pérdida de una parte importante de su narcisismo, ligado a él, a una sensación de vaciamiento o mutilación que le resulta intolerable. Es esta pérdida la que está en el origen de la deseada reconciliación. La fase de luna de miel tiene un efecto de seducción en la mujer (aumentando su narcisismo: él la ama) hasta llegar a un aumento de sentimientos positivos, olvido selectivo, separación de la parte mala del otro. Es aquí donde cabe interpretar la percepción que las propias mujeres tienen de haber "provocado", a veces, el episodio de malos tratos. Para disminuir la tensión, la mujer puede anticipar la crisis, en un esfuerzo por controlarla y provocar así, no sólo la violencia, sino la calma que le precede.Vemos pues, los efectos claros de disociación que van a impedir la percepción realista del otro.

Existe un amplio consenso en considerar que esta actitud de la mujer tiene que ver con su identidad de género, con la idea de feminidad que la sustenta, adquirida a través de generaciones de mujeres, y en cómo esa identidad comporta determinados ingredientes que van a facilitar su posición como objeto del hombre y su consecuente pasividad.

Desde la adolescencia, el cuerpo y el psiquismo de la mujer es objeto de violencia real o fantaseada. Las chicas temen más que los chicos las agresiones sexuales; la mujer, en nuestra sociedad está colocada del lado de la víctima (39).

En un estudio reciente sobre la representación del amor, la mujer y el sexo en el cine español de los 90 (40), la autora destaca que en todas las películas analizadas, los estereotipos de género siguen siendo los tradicionales, es más, como dato relevante, la violación es contemplada como un hecho jocoso, y la mujer considerada en el acto amoroso como mero objeto sexual (prevalecen como representación del placer sexual de la pareja coitos de escasos segundos, sin juego erótico que les anteceda), es decir, el cine sigue mostrando como universal las expectativas que sobre la mujer ha creado el género masculino y los viejos estereotipos de género ligados a éstas. Y el cine, hoy, en uno de los maestros privilegiados de nuestra educación sentimental.

Estos estereotipos conducen a que algunas mujeres vivan su feminidad como una amenaza, una debilidad, y requieran del amor de un hombre para salvarse. Podemos decir, aunque esto nos llevaría todo un desarrollo paralelo, que en su psiquismo, tal y como es construido en nuestra sociedad actual, la mujer necesita de un hombre para sostenerse. Primero del padre, luego de su pareja.

Corsi señalará cómo en estas parejas la relación se establece entre mujeres hiperfemeninas y hombres hipermasculinos, y Dio Bleichmar apunta que a más identificación con la feminidad tradicional más dependencia a los juicios del otro tendrá la mujer.

Las mujeres que se vinculan a hombres maltratadores y que permanecen ligadas a él reconocen la dependencia del hombre que aman y se "enganchan" a él porque esa dependencia les produce una satisfacción narcisista, un sentimiento de dominio, de ser necesaria para 
el otro, imprescindible para él. Son mujeres identificadas con la feminidad más convencional, enfermas de esa feminidad, que se prestan a ser objetos del hombre porque este hombre que las secuestra de los otros se convierte y es para ellas el soporte fundamental de su narcisismo tanto como el rol de mujer de este hombre lo es de su incipiente identidad.

Su fácil victimización tiene que ver con ese lugar asignado socialmente a lo femenino, «la víctima siente vergüenza de las acciones de violencia... Esa actitud de la mujer deriva sin duda de las ideas que desde niña se le inculcaron, por virtud de los que Kenneth Bouldig ha llamado la trampa del sacrificio y Betty Friedan, por su parte, la 'mística de la feminidad'» (41).

Además de los mecanismos inconscientes descritos, queremos destacar la complementariedad entre la tendencia a la autoinculpación de la mujer frente a la de exculpación en los hombres, ambas fruto del aprendizaje de la identidad de género, así como el compromiso del cuerpo femenino maltratado en la actuación de la violencia en la pareja, compromiso común en tantos otros síntomas que afectan a las mujeres.

Lorente Acosta, en la obra citada, recoge algunas opiniones sobre los mecanismos que explican lo que acontece en la mujer víctima de los malos tratos:

1. Se les ha asimilado con lo que sucede en el Síndrome de Estocolmo, esclavas psicológicas de su secuestrador, que se convierte en el único vínculo afectivo que tienen, además de los hijos, a los que debe prestarse y sacrificar su vida, según el estereotipo de la buena madre.

2. Se ha explicado su sometimiento como una "identificación con el agresor", mecanismo descrito por Anna Freud que explica cómo la víctima, se identifica con su verdugo como una forma de defenderse del peligro que le acecha e intentar controlarlo mejor. El abandono típico de la subjetividad y de los deseos de la mujer que se produce durante el proceso de socialización, con la reducción de la actividad de las mujeres a la esfera doméstica (42), comporta dejarse entre paréntesis para atender las necesidades del marido, lo que constituye un hecho frecuente. Cuando las necesidades son las de un maltratador, la mujer se coloca como víctima.

3. Susan Painter y D.G. Dutton hablan de unión o lazo traumático entre ambos miembros de la pareja, pero con la circunstancia de que el poder está de parte del hombre.

Otro autor, Domingo Carotozzolo (43), desarrolla una hipótesis sobre la formación en la pareja de lo que denomina "vínculo excitante", que tiene por objeto "el avance de cada uno de los sujetos en el aparato psíquico del otro y su paulatina conquista total. Se logrará de esta forma ser todo para el otro y ofrecerse para colmarlo". De este modo se «recrea una vinculación narcisista en la cual el sujeto 'habita' en la otra persona, reproduciendo un estado privilegiado y único como aquél que existía en el vientre materno». En esta patología vincular así descrita «la agresion es el arma necesaria para 'penetrar' en el otro, para 'conquistarlo', 'poseerlo', habitar en él como único huésped. En este sentido 
une más que el amor». No nos aventuramos a llevar a la memoria del estado prenatal el anhelo de un vínculo de fusión semejante, preferimos situarlo en los primeros momentos de la interacción del bebé con su madre, y las representaciones que de este vínculo se irán creando en el psiquismo infantil, siguiendo a Stern y Bollas.

Como constatan los diferentes estudios, la relación entre la víctima y su agresor contenía desde su origen los elementos del sometimiento. Remitimos a la obra de Benjamin para analizar la relación entre dominación y sometimiento a la luz de la dialéctica hegeliana del amo y del esclavo y sus aportaciones sobre el reconocimiento que hemos utilizado en este trabajo. Posteriormente este sometimiento se acentuará cuando el marido tenga la plena seguridad de poseer a su objeto y el proceso de desubjetivación de la mujer se haya completado.

La separación de los cónyuges supone una mutilación de partes fundamentales de la valía de cada uno que se han ligado al otro, de ahí la indestructibilidad de un vínculo paradójicamente destructivo. Ahí está el nudo gordiano que desespera y hace incomprensible la relación para los profesionales que les atienden.

Más allá de las condiciones que ha de sufrir la mujer para establecerse en esa relación patológica, el maltrato reiterado producirá por sí mismo en ella una serie de consecuencias crónicas, de efectos secundarios, un deterioro psíquico progresivo que acentúa la inicial indefensión. Deterioro que ha sido más estudiado que sus antecedentes, y que se expresa, según los autores consultados, utilizando la terminología psicológica común, como:

- Baja autoestima.

- Depresión (desvalorización y agresión vuelta sobre ella misma).

- Desamparo e impotencia (indefensión: la arbitrariedad y el descontrol sobre las crisis del hombre le conducen a la sensación de que "haga lo que haga es igual").

A los mecanismos inconscientes descritos y a las consecuencias del maltrato citadas hay que añadir las reiteradas razones socioculturales que favorecen la permanencia de la mujer con la pareja de la que recibe maltrato:

- Falta de alternativas.

- Temor a la desaprobación familiar y de los amigos: la sociedad culpa sutilmente a la mujer de la agresión y del fracaso de las relaciones de pareja. Los profesionales que intervienen (policías, jueces), suelen tener una visión machista de la situación. Es necesario indicar aquí que como profesionales estamos afectados por los mismos prejuicios de género que el resto de la sociedad, por lo que hay que cuidar extremadamente, más en este tipo de problemática, que nuestra interpretación de los hechos no esté afectada por estereotipos de género que atraviesan incluso nuestras teorías y marcos de referencia.

- Preocupación por la pérdida del hogar. Unida al aislamiento contribuye a la indefensión, puesto que es otro sostén narcisista que teme perder.

- Miedo a las represalias del marido. Es frecuente que las agresiones se produzcan cuan- 
do se ha llevado a cabo la separación por parte de la mujer. A la ferocidad de la violencia actual, que a menudo tiene consecuencias mortales, han colaborado los cambios sociales en la representación de la masculinidad que se desvía de los emblemas tradicionales. El hombre violento conoce el rechazo que la sociedad va generando hacia su comportamiento, lo que aumenta la contradicción y la angustia a la que se enfrenta.

Estos cambios van acompañados en nuestra cultura de la globalización de un incremento del ideal de individualismo y autosuficiencia. Como señala Lipovetsky (44): "las relaciones entre los sexos están cada vez menos regidas por la "tradición" o la "fuerza" y cada vez más por la lógica expansiva de los derechos individuales a la autonomía y a la dignidad". En el mismo sentido que Lipovetsky, y desde una perspectiva coherentemente economicista, Fernando Esteve Mora en un artículo publicado en el diario El País, martes $22-12-1.998$, señala que hay episodios de violencia en el $30 \%$ de las parejas norteamericanas. El autor mantiene una tesis sobre la violencia ligada a la economía que resulta de interés: de una familia cooperativa, con roles complementarios y tradicionales entre el hombre y la mujer, hemos pasado, a partir de los años sesenta, gracias a las batallas de las feministas, a una familia que se contempla como una interacción no cooperativa donde cada cónyuge trata de satisfacer al máximo sus propias preferencias con la limitación de que no puede obligar al otro a permanecer en la familia si su bienestar dentro de ella es inferior al bienestar que alcanzaría fuera. La violencia es uno de los medios para satisfacer los intereses de uno de los miembros. Pero la agresividad tiene que permanecer contenida dentro de ciertos límites, para no provocar el abandono (el amo necesita del esclavo, diríamos nosotros).

La tesis de este autor se centra en que los agresores se comportan como si "compraran" el aguante de su pareja. De ahí que cuanta más renta posea la mujer, y cuantos menos hijos tenga la pareja, menos violencia se produzca. Para el autor las casas de acogida ayudan a disminuir la violencia porque sirven de límite, pues, aunque la mujer vuelva con el marido, le señala de ese modo lo que puede pagar y lo que no tiene precio.

Para terminar, es fácil deducir por todo lo anterior, que la intervención en este tipo de parejas no puede ser meramente social. Dado que la estructura personal de ambos será la misma aunque se produzca la separación, la secuencia puede volver a repetirse en futuras uniones, lo cual es frecuente en nuestra experiencia, aunque la literatura muestre datos contradictorios al respecto. Es por eso que son necesarias intervenciones que vayan más allá de la acogida y contemplen el tratamiento psicoterapeútico tanto de la mujer víctima de los malos tratos como del hombre que los inflige. 


\section{BIBLIOGRAFIA}

(1) Von Feuerbahc: Gaspar Hauser. Un delito contra el alma del hombre. Madrid, AEN 1.997.

(2) Itard, Jean.: Victor de Aveyron, Madrid, Alianza 1.973

(3) Spindler, G. D.: "La transmisión de la cultura" en Honorio M. Velasco Maillo y otros (ed.) Lecturas de antropología para educadores. Madrid, editorial Trotta S.A, 1.993

(4) Freud, S: Psicología de las masas y análisis del yo, capítulo VII, Tomo III, Madrid, Biblioteca Nueva, $3^{\circ}$ edición, 1.973.

(5) Fonagy, P.: "Persistencia transgeneracional del apego: una nueva teoría" en Aperturas Psicoanalíticas, $\mathrm{N}^{\circ} 3$, Noviembre 1.999 , revista virtual.

(6) Stern, D.N.: La constelación maternal, Madrid, Paidós, 1.997

(7) Benjamin; J.: Sujetos iguales, objetos de amor. Ensayos sobre el reconocimiento y la diferencia sexual, Buenos Aires, Paidós, 1.997.

(8) Bollas, C.: La sombra del objeto. Psicoanálisis de lo sabido no pensado Buenos Aires, Amorrortu, 1.991.

(9) Sanfeliu, I. coord.: Nuevos paradigmas psicoanalíticos, Madrid, Quipu ediciones, 1.996.

(10) Velázquez, S.: "Extraños en la noche. La violencia sexual en la pareja ", en Mabel Burín, Dio Bleichmar: Género, psicoanálisis, subjetividad, Buenos Aires, Paidós, 1.996, $1^{\text {a }}$ ed. Velázquez cita a Collin F.: "Sobre el amor: conversación con Julia Kristeva”, México, Copilco, Debate Feminista, año 2, vol 4, septiembre de 1.991.

(11) Benjamin, J: Los lazos de amor. Psicoanálisis, feminismo y el problema de la dominación. Buenos Aires, Paidós, 1.996.

(12) Stoller, R.J.: Sex and Gender, Nueva York, Jason Aronson, 1.975

(13) Kaplan, L.: Adolescencia. El adiós a la infancia,Buenos Aires, Paidós, 1.991.

(14) Heritier, F.: Masculino/Femenino. El pensamiento de la diferencia. Barcelona, Ariel, 1.996.

(15) Bordieu, P.: La dominación masculina. Barcelona, Anagrama 2.000.

(16) Lorite Mena, J.: El orden femenino. Origen de un simulacro cultural, Barcelona. Editorial Anthropos, 1.987.

(17) Corsi, J.: Violencia masculina en la pareja, Buenos Aires, Paidós, 1.995, $1^{\circ}$ edición.

(18) Velasco Maillo, Honorio M., y otros: Lecturas de antropología para educadores, Madrid, Editorial Trotta, 1.993.

(19) Herdt, G.h.: Homosexualidad ritual en Melanesia, Madrid, Fundación Universidad empresa, 1.992

(20) Braconnier, A.: El sexo de las emociones, Barcelona, Editorial Andrés Bello Española, 1.997.

(21) Bonino, L.: Varones, género y Salud Mental, Ponencia presentada en las X Jornadas de la Asociación Española de Neuropsiquiatría, Palma, noviembre de 1.999.

(22) Echeburúa E.; De Corral, P.: Manual de violencia familiar, Madrid, Siglo XXI editores, 1.998.

(23) Mead, M.: Sexo y temperamento en las sociedades primitivas, Barcelona, Editorial Laia, 1.973, $3^{\circ}$ edición.

(24) Torrente Acosta, M. y J.A.: Agresión a la mujer: maltrato, violación y acoso, Granada. Editorial Comares, 1.998.

(25) Freud, S.. Psicología de las masas y análisis del yo, Madrid, Biblioteca Nueva, tomo III, $3^{\circ}$ edición, 1.973.

(26) Freud, S., obra citada, capítulo VIII "Enamoramiento e Hipnosis".

(27) López Mondéjar, L.: "Tenemos que hablar...consideraciones sobre el amor contemporáneo" Madrid, Revista de la AEN, $\mathrm{n}^{\circ} 72,1.999$.

(28) Bonino, L.: obra citada

(29) Bollas, C.: obra citada 
(30) Hannath, A.: Eichmann en Jerusalén. Un estudio sobre la banalidad del mal, Barcelona, Lumen, $1.999,2^{\mathrm{a}}$ edición.

(31) Levi, P.: véase su trilogía: Si esto es un hombre, La tregua, Los hundidos y salvados, Barcelona, Muchnik editores, $1.997,3^{\mathrm{a}}$ edición.

(32) Bauman, Z.: Modernidad y Holocausto, Ediciones Seguitur, Madrid 1.997.

(33) Lorente Acosta: obra citada

(34) Lacan, J.: " El estadio del espejo como formador de la función del yo (je)..."en "Escritos I", Madrid, Siglo XXI editores S.A., $10^{a}$ ed,. 1.984

(35) Stoller, R.J.: Dolor y pasión. Un psicoanalista explora el mundo sadomasoquista, Buenos Aires, Manantial, 1.998.

(36) Welldon, E.V.: Madre, virgen, puta. Idealización y denigración de la maternidad Madrid, Siglo Veintiuno editores, 1.993.

(37) Kaplan, L.: Perversiones femeninas. Las tentaciones de Emma Bovary, Barcelona, Paidós, $1.994,1^{2}$ ed.

(38) Dio Bleichmar, E.: La depresión en la mujer, Madrid, Temas de Hoy, 1.999.

(39) Dio Bleichmar, E.: La sexualidad femenina de la niña a la mujer, Barcelona, Paidós, 1.997.

(40) Aguilar, P: Mujer, amor y sexo en el cine español de los 90, Madrid, Editorial Fundamentos, 1.998.

(41) Pérez del Campo, N. AM.: Una cuestión incomprendida. El maltrato a la mujer, Madrid, Horas y Horas, La editorial, 1.995

(42) Del Valle, T., Sanz R.C.: Género y sexualidad, Madrid, Fundación Universidad Empresa, 1.991

(43) Carotozzolo, D.: La pareja violenta. Una lectura psicoanalítica, Rosario, Homo Sapiens, 1.997

(44) Lipovetsky, G.: El crepúsculo del deber. La ética indolora de los nuevos tiempos democráticos, Barcelona, Anagrama, 1.994.

Otra bibliografía consultada:

- Para introducirse en las representaciones que los medios de comunicación, El País y ABC, y las instituciones públicas que se relacionan con la violencia familiar han ido elaborando sobre ésta, consúltese el volumen de la ASOCIACION PRO DERECHOS HUMANOS: La violencia familiar. Actitudes y representaciones sociales, Madrid, Editorial Fundamentos, 1.999.

- Cuando pensábamos que habíamos concluido este artículo, cayó en nuestras manos el libro de Rosalind Minsky "Psicoanálisis y cultura" Madrid, Ediciones Cátedra S.A., 2.000, cuya lectura nos obligó a añadirlo a esta bibliografía. La autora sigue la obra de Winnicott y Bollas en diferentes aspectos; al tratar brevemente la violencia hacia las mujeres, constata lo siguiente: "Así afirma tanto Winnicott como Klein, la violencia específica contra las mujeres puede contener en algunos hombres una mezcla de envidia y miedo a la aniquilación, inspirado por el poder de la madre" (pag, 213).

Nos pareció muy rico la puesta en juego del concepto "odio amoroso", de Bion, que explicita la tensión entre los dos afectos: "el niño teme al abandono, lo cual le causa un odio inmenso, pero también atesora a la madre, pues es todo lo que tiene", para contribuir al estudio de los vínculos entre maltratador y víctima.

* Psicóloga clínica. Psicoanalista.

Consulta privada

Correspondencia: Gran Vía 28, $3^{\circ}$ izqda. 30.005 Murcia

e-mail: lolamondej@correo.cop.es

Fecha de recepción: 8-V-2000 